\title{
PERANAN WANITA DALAM PERJUANGAN KEMERDEKAAN INDONESIA MASA PENDUDUKAN JEPANG
}

\author{
Wulan Sondarika \\ Program Studi Pendidikan Sejarah FKIP Universitas Galuh, Ciamis \\ e-mail: wulansondarika@gmail.com
}

\begin{abstract}
Abstrak
Tujuan dari penelitian ini adalah untuk mengetahui eksistensi kaum wanita di Indonesia dan peranan wanita dalam perjuangan kemerdekaan Indonesia masa pendudukan Jepang. Metode penelitian yang digunakan adalah metode sejarah atau historis, degan tahapan; heuristik, kritik, interprestasi dan historiografi. Teknik pengumpulan data yang digunakan adalah observasi, wawancara dan studi kepustakaan. Hasil dari penelitian yaitu bahwa wanita Indonesia sejak zaman dulunya terutama zaman Jepang sangat berperan aktif. Baik itu aktif di dalam organisasi maupun aktif dalam kegiatan-kegiatan sosial.
\end{abstract}

Kata kunci:peranan wanita, kemerdekaan Indonesia, pendudukan Jepang

\begin{abstract}
The purpose of this study is to know the existence of women in Indonesia and the role of women in the struggle for Indonesian independence during the occupation of Japan. The research method used is historical or historical method, with stages; Heuristics, criticism, interpretation and historiography. Data collection techniques used are observation, interview and literature study. The result of the research is that Indonesian women since ancient times especially the Japanese era is very active role. Whether it is active in the organization or active in social activities.
\end{abstract}

Keywords: the role of women, Indonesian independence, Japanese occupation

\section{PENDAHULUAN}

Masa pendudukan Jepang selama tiga setengah tahun (1942-1945) merupakan salah satu periode yang paling menentukan dalam sejarah Indonesia. Sebelum Jepang memasuki wilayah Indonesia, tidak ada satupun tantangan yang serius terhadap kekuasaan Belanda di Indonesia. Pada waktu Jepang menyerah telah berlangsung begitu banyak perubahan luar biasa yang memungkinkan terjadinya revolusi Indonesia. Jepang memberi sumbangan langsung pada perkembanganperkembangan tersebut. Terutama di Jawa, dan sampai tingkatan yang lebih kecil di Sumatra, mereka mengindoktrinasi, melatih dan mempersenjatai banyak dari generasi muda serta memberi kesempatan kepada para pemimpin yang lebih tua untuk menjalin hubungan dengan rakyat. Di seluruh Nusantara mereka mempolitisasikan bangsa Indonesia sampai pada tingkat desa dengan sengaja dan dengan menghadapkan Indonesia pada rezim kolonial yang bersifat sangat menindas dan merusak dalam sejarahnya. Pada waktu Jepang menyerah telah berlangsung begitu banyak perubahan luar biasa yang memungkinkan terjadinya revolusi Indonesia (Ricklefs, 2011: 297). 
Kebijakan-kebijakan Jepang di Indonesia membangkitkan rasa kesadaran nasional yang jauh lebih mantap daripada masa kolonial Hindia Belanda. Jepang melibatkan seluruh potensi dan komponen dalam masyarakat Indonesia. Pada masa pendudukan Jepang, para pemuda Indonesia mendapat kesempatan berlatih militer yang terhimpun dalam PETA (Pembela Tanah Air). Begitu pula dengan para tokoh dari golongan tua mendapat kesempatan berorganisasi melalui tiga serangkai, Chou Sangi In, BPUPKI dan PPKI.

Terutama setelah kekuatan Jepang mulai melemah pada pertengahan tahun 1942, Jepang berusaha untuk bertahan menghadapi serangan Sekutu. Sekutu menyerang pertahanan Jepang di Pasifik dan hampir seluruh medan perang tersebut dimenangkan oleh Sekutu. Mundurnya kekuatan Jepang mendorong pemerintah kolonial Jepang untuk melakukan politik partisipasi terhadap bangsa Indonesia. Berdasarkan keputusan sidang parlemen ke-82 di Tokyo, Perdana Menteri Tokyo memberikan janji kemerdekaan kepada bangsa Indonesia untuk turut mengambil bagian dalam pemerintahan negara.

Jepang menghimpun kekuatan masa yang ada untuk dilibatkan dalam perang dan diberi wadah dalam organisasi. Barisan pemuda dimasukkan dalam Seinendan dan tugas pembantu polisi ditempatkan dalam Keibodan.
Mereka dididik latihan militer dasar dengan menggunakan bambu runcing dan senjata tiruan. Perempuan juga dikerahkan dalam organisasi Fujinkai. (Suhartono dan Syambul Rizal, 2006:160).

\section{Arti, Kedudukan, dan Peranan Wanita}

Secara biologis wanita dan pria memang tidak sama, akan tetapi sebagai mahluk sosial yang dilengkapi dengan akal dan budi dan kehendak merdeka, kedua macam insan itu mempunyai persamaan yang hakiki. Keduanya adalah pribadi yang mempunyai hak sama untuk berkembang. Namun dalam kenyataannya, baik dinegara maju maupun di negara berkembang, wanita dianggap sebagai warga negara kelas dua, yang selalu mengalami kesulitan untuk dapat menikmati hak yang dimilikinya. (Hadriana Marhaeni Munthe, 2003: 10).

$$
\text { Wanita dikategorikan sebagai }
$$

“kelamin kedua” yang berada dibawah subordinasi pria, antara lain dapat dicari pada pelacakan kaum arkeolog yang meneliti kehidupan dan kebudayaan penduduk pada zaman pra-sejarah. Diantara hasil penelitian zaman Paleolithikum sebuah periode yang sangat panjang dan berakhir pada sekitar tahun $12.000 \mathrm{SM}$, penduduknya adalah pengumpul pangan dan pemburu hewan serta ikan. Para ahli filsafat abad ke-XVIII dan abad ke-XIX menganggap bahwa kaum wanita lebih lemah daripada pria. Tokoh pemikir Inggris yang berhaluan liberal 
mendasarkan falsafah liberal, yaitu bahwa semua orang diciptakan dengan hak-hak yang sama dan setiap orang harus mempunyai kesempatan yang sama untuk memajukan dirinya. Dalam melaksanakan kebebasan mengembangkan bakat, wanita memilih rumah tangga, sedangkan kaum laki-laki memilih kehidupan profesi. (Maria Ulfah Subandio dkk, 1983: 55).

Montagu mengemukakan bahwa sifat-sifat psikologis wanita membuktikan lebih unggul daripada laki-laki. Selain itu terdapat fakta-fakta yang membuktikan bahwa wanita adalah organisme yang secara biologis lebih unggul, unggul dalam arti menikmati nilai kelangsungan hidup yang lebih tinggi daripada pria berkat sifat-sifat biologisnya. Tokoh lainnya adalah Freud (1856-1939) mengemukakan bahwa dunia adalah dunianya pria. Wanita diukur dengan kacamata apa yang berlaku bagi pria dan apa yang ditentukan oleh pria. Pandangan Freud ini dikenal dengan phalocentric, pada penekanannya pada organ kelamin pria sebagai sumber kekuasaan. (Saparinah Sadili, 1988: 33).

Pemikiran teoritis di atas menunjukkan bahwa masalah wanita dalam hubungannya dengan pria mencakup dua bagian. Pertama, pemikiran yang dipengaruhi oleh pendekatan biologis yang tidak memberi pertimbangan pada unsur sosial-budaya. Ini berarti bahwa faktor-faktor luar hampir tidak berpengaruh sama sekali. Kedua, pemikiran yang dipengaruhi oleh pendekatan sosial-budaya yang mempertimbangkan peranan besar dari kekuatan-kekuatan luar.

Di Indonesia gerakan emansipasi dilakukan oleh organisasi-organisasi wanita berlandaskan pada gagasan Kartini. Kartini menuntut pendidikan bagi wanita, berarti orientasinya lebih ditekankan pada tingkatan kecerdasan secara individual. Sasaran yang ingin lebih jauh capai adalah mengangkat martabat kaumnya, sehingga sejajar dengan martabat kaum pria. Dengan demikian, maka gerakan emansipasi yang dilakukan oleh kaum wanita dari ketergantungan pada orang lain terutama pada kaum lakilaki. Tujuan gerakan itu agar wanita dapat hidup mandiri, menggunakan hakhaknya seperti halnya yang berlaku pada kaum laki-laki, sehingga mereka tidak lagi menyandang sebutan "warga negara kelas dua".

Bertolak dari gagasan Kartini yang menuntut pendidikan bagi kaumnya dan menyadari adanya ketidakadilan, maka dalam Kongres Perempuan I (1928) memasukkan pendidikan untuk anak-anak perempuan dan usaha perlindungan wanita dalam perkawinan sebagai program perjuangan. Menurut Cokrowinoto dkk, (198: 27)bahwa dalam sejarah pergerakan nasional disebutkan dalam usaha mencapai kemerdekaan negara dan bangsaya kaum wanita melakukan kerjasama dengan kaum pria. Prinsip kerjasama itu tetap dipegang dan 
dapat dibuktikan pada waktu perang kemerdekaan dan pada masa pembangunan nasional.

Wanita Indonesia dalam Lintasan Sejarah

Sejak awal abad ke-19, beberapa wanita Indonesia telah tampil dipanggung sejarah secara perorangan dalam membela tanah air dan bangsanya, misalnya Nyi Ageng Serang XIX, Christina Martha Tiahahu (1817-1819), Cut Nyak Dien (1873-1904), R.A. Kartini (18791904), Dewi Sartika (1884-1947), Maria Walanda Maramis (1872-1924), Nyai Ahmad Dahlan (1872-1936). Namun masa yang amat penting dan itu menjadi titik balik dari perjuangan gerakan perempuan adalah pada tahun 1928, saat dimana diadakan Kongres Perempuan yang pertama di Yogyakarta, dan Soekarno yang kemudian yang menjadi presiden RI memberikan kata sambutan. (Mukmin, 1980: 78).

Usaha-usaha yang dilakukan Dewi Sartika sejak tahun 1904 dengan kemampuan yang ada padanya, ia membuka semacam bentuk pendidikan untuk memberi pengajaran dan peningkatan keterampilan khusus wanita. Pendidikan yang di koordinasikan oleh Dewi Sartika kemudian dikenal dengan Sekolah Istriatau Sekolah Gadis yang dibuka pada 16 Januari 1904. Sekolah yang dimulai dibuka di daerah Paseban Bandungitu, ternyata mempunyai pengaruh yang cukup luas. Anak-anak gadis atau kaum wanita yang telah tamat dari Sekolah Istri (Kautaman Istri) dapat mendirikan sekolah-sekolah yang sama ditempat lain. Secara sporadis sekolahsekolah seperti itu dibuka dan perkumpulan-perkumpulan serta bentuk kelompok terbatas tumbuh dimanadimana. (Rochiati Wiraatmadja, 1986: 108).

Selain itu adapula perkumpulan wanita yang bersifat keagamaan (Islam) dengan nama "Sopo Tresno" (1914) yang kemudian pada tahun 1917 menjadi bagian wanita dari Muhammdiyah dengan nama Aisyiyah. Sarikat Siti Fatimah berdiri di Garut sebagai bagian dari Sarikat Islam dan di Yogyakarta dengan nama "Wanodya Utomo" pada tahun 1925 bernama "Sarikat Putri Islam" (Hadriana Marhaeni Munthe, 2003: 15).

Setelah tahun 1920-an, jumlah perkumpulan wanita semakin banyak. Timbul perkumpulan-perkumpulan wanita yangbergerak dalam kegiatan sosial dan kemasyarakatan yang sifatnyapun lebih luas dari perkumpulan sebelumnya disamping jumlahnya yang bertambah. Hal itu disebabkan karena kesediaan serta kesadaran wanita untuk terlibat dalam kegiatan organisasi lebih meningkat dan kecakapan bertindak dalam berorganisasi semakin maju. Selain itu organisasi politik juga memberi perhatian kepada wanita dan menyokong pendirian bagian dari organisasi bersangkutan. 
Ternyata tidak hanya kaum pria saja, kaum wanita pun turut serta dalam memperjuangkan kemerdekaan Indonesia dari pendudukan Jepang. Sehingga kajian ini akan membahas tentang eksistensi kaum wanita di Indonesia pada masa pendudukan Jepang, serta peranan wanita dalam perjuangan kemerdekaan Indonesia pada masa pendudukan Jepang.

\section{METODE}

Kajian ini menggunakan metode historis dalam penelaahannya, meliputi tahapan sebagai berikut 1) Heuristik, yakni tahap dimana pencarian sumber-sumber sejarah atau jejak, fakta, dan data masa lampau; 2) Kritik, yakni tahap pengujian terhadap sumber yang telah diperoleh untuk menentukan keaslian dan kevalidan sumber tersebut; 3) Interpretasi, adalah tahap penafsiran dan analisis terhadap data dan fakta yang telah terkumpul; 4) Historiografi, yakni tahap penulisan sejarah setelah melalui langkah-langkah di atas.

Sedangkan teknik pengumpulan data yang dilakukan adalah melalui studi literatur atau studi kepustakaan yakni dengan mengumpulkan sumber-sumber yang sesuai (Sugiyono, 2012:283).

\section{HASIL DAN PEMBAHASAN}

\section{Kegiatan Wanita Pada Badan Resmi Jepang \\ Pada masa pendudukan Jepang wanita tidak banyak memperoleh kesempatan,}

karena setiap gerak selalu mendapat pengawasan yang ketat dari kempetai Jepang. Untuk mengikuti kehendak Pemerintahan Jepang maka ketika didirikan Gerakan Tiga A dibentuk pula gerakan Istri Tiga A dengan pimpinannya Ny. Artinah Syamsuddin. Gerakan tersebut dilengkapi dengan bagian puteri, yang dinamakan Barisan Putri Asia Raya. Dengan dibentuknya PUTERA pada bulanMaret 1943, dibentuk pula barisan pekerjaan perempuan PUTERA, bagian dari wanitanya. (Manus, 1985: 84).

Disamping gerakan itu, pemerintah Jepang mendirikan Fujinkai (Organisasi Wanita) yang kedudukannya khusus menampung segala bentuk kegatan wanita. Fujinkai didirikan mulai dari tingkat pusat sampai ke tingkat bawah dan namanya sesuai dengan tingkat dan tempat kedudukannya, seperti ken untuk tingkat kabupaten dan si untuk kota. Adapun pemimpin dari perkumpulan ini adalah istri-istri dari kenko (bupati). Dengan demikian Fujinkai merupakan suatu keharusan bagi ibu-ibu atau para pamong praja mulai dari tingkat atas sampai ke wilayah kecamatankecamatan. Anggota-anggotanya wajib menggerakkan tenaga-tenaga kaum wanita di tempat masing-masing, sedangkan yang turut menjadi anggota adalah anak gadis berumur 15 tahun ke atas. Keanggotaan Fujinkai juga terbuka bagi orang-orang asing (Panita Kongres Wanita Indonesia, 1986: 85). 
Pada tanggal 3 Nopember 1943 di Jakarta didirikan Tokobetsusi dengan pimpinannya Ny. RA. Abdirrachman. Perkumpulan ini kemudian dilengkapi dengan didirikannya Barisan Putri dengan pimpinan Siti Dahlia dan Nursyamsu sebagai wakilnya. Adapun para pembantunya antara lain adalah Setiati, Malidar dan Paramitra Rahayu Abdurrachman. (Mukmin, 1980: 86-87).

Dalam rangka pencetakan kader, Barisan Puteri melaksanakan latihanlatihan yang bertempat di Bioskop Megaria Jakarta. Kegiatan tersebut dilakukan secara bertahap dan diikuti oleh 50 orang. Para pesertanya terdiri atas gadis-gadis sebagai wakil dari kecamatan-kecamatan seluruh Jakarta dan diluar Jakarta. Pelajaran diberikan adalah latihan kemiliteran, PKK, kepalang-merahan dan lain-lain. Selain itu terdapat keterampilan seperti memintal benang, menenun, berlatih menyanyi dan siaran radio. Untuk menambah wawasan setiap dua hari sekali selalu diadakan ceramah dari tokoh nasional diantaranya ialah Muhammad Hatta dan Sutan Syahrir (Panitia Kongres Wanita, 1985: 85).

Pada 1 Maret 1944 PUTERA dibubarkan dan dilebur menjadi Jawa Hokokai. Dengan susunan pengurusnya antara lain:

Ketua : Ny. Sunarso Mangunpuspito

Wakil Ketua I : Ny. los Wiraatmaja

Wakil Ketua II : Ny. Maskun

\author{
Penulis I : Ny. Maryati Adnan \\ Penulis II : : Ny. Rosnah Jamin \\ Anggota : Ny. Siti Maryam \\ Pembantu : Ny. Sutarman \\ Ny. S.R. Tambunan \\ Ny. Artinah Syamsudin \\ Ny. Hafni Abu Hanifah
}

Pada Januari 1945 Jawa Hokokai berdiri sendiri dengan nama Jawa HokokaiFujinkai Jimukyoku, dan pemudinya disebut Joahi Seinenkai dengan pimpinannya Siti Maryono, Ny. Maryati Adnan dan Ny. Rosnah Jamin.

Berhubungan barisan tersebut dipersiapkan di belakang garis perang, maka kepada barisan ini diberikan latihan kepalang-merahan, baris-berbaris, mempergunakan senjata, latihan bahaya udara, mengunjungi rumah sakit, mengadakan dapur umum, dapur keliling, dapur tetap dan dapur pembelaan.

Usaha-usaha yang dilakukan

Fujinkai antara lain:

a. Mengobarkan semangat cinta tanah air dan bangsa dikalangan wanita dan menanamkan nasionalisme;

b. Menganjurkan agar suka berkorban dan rela menderita untuk tanah air dan bangsa;

c. Menyiapkan tenaga untuk ikut serta dibelakang garis peperangan;

d. Menganjurkan hidup teratur dan berhemat;

e. Memperbanyak hasil bumi dengan menanami semua tanah dengan tanaman penghasil bahan makanan dan pakaian antara lain ubi, jarak, kapas dan lain-lain;

f. Menghidupkan pekerjaan tangan dan indutri di rumah antara lain memintal benang, membuat kaos kaki; 
g. Mengadakan latihan-latihan yang diperlukan;

h. Menghidupkan pekerjaan untuk memberantas pengangguran.

(Lasmidjah, 1982: 30).

Dilihat dari kegiatan-kegiatan yang dilakukan Fujinkai pada hakikatnya tidaklah terlepas dari garis-garis yang telah ditentukan seperti yang tertuang dalam Jawa Hokokai yang mencakup pelaksanaan segala sesuatu dengan nyata dan ikhlas untuk menyumbangkan segenap tenaga berdasarkan semangat persaudaraan antara semua bangsa dan untuk memperkokoh pembelaan tanah air.

Pertengahan tahun 1944 kekuatan Angkatan Perang Jepang semakin terdesak oleh kekuatan Sekutu. Sehubungan dengan keadaan tersebut, pemerintah Jepang selain dari badanbadan yang telah ada seperti Keibondan (Pembantu Polisi), Seinendan (Barisan Pemuda), Heiho (Pembantu Prajurit), dan PETA (Pembela Tanah Air) juga merasa perlu membentuk barisan Srikandi dan badan ini merupakan bagian dari Fujinkai. Pasukan ini benar-benar dipersiapkan sebagai pasukan tempur, karena mereka telah dibekali dengan berbagai pengetahuan tentang kemiliteran, sehingga pasukan tersebut sudah memiliki keterampilan dan kemampuan yang cukup. (Manus, 1985: 23).

Pada masa akhir pemerintahan pendudukan Jepang, keadaan diwarnai kesusahan, sandang-pangan susah didapat, romusha tersebar sampai ke Asia daratan sebagai tenaga kerja paksa serta tiba gilirannya menjadi manusia yang disia-siakan karena tidak lagi mendapat perhatian yang layak, karena itu banyak diantara mereka yang hilang begitu saja. Untuk pulang ke kampung halaman tidak ada daya untuk mendukungnya. Untuk mengimbangi keadaan yang semakin genting tersebut kaum wanita yang berpayung Fujinkai turun ke lapangan untuk memberikan peneranganpenerangan terhadap kaum ibu di diwilayah Tanorigumi (Rukun Tetangga) dalam usaha melakukan gerakan penghematan. Selain itu juga turut mengerjakan sawah dan ladang seperti mengetam padi, menanam kapas dan jarak (Lasmidjah Hardi, 1985: 121).

Guna meringankan beban penderitaan Romusha, Fujinkai secara sukarela bergerak mengumpulkan pakaian-pakaian bekas yang kemudian diberikan kepada Romusha. Karena sulitnya mendapatkan bahan pakaian, maka untuk keperluan tersebut terpaksa membuat pakaian dari bahan karung goni seperti yang dilakukan FujinkaiSurabaya sekedar meringankan penderitaan romusha yang sedang bekerja di pantai selatan pulau Jawa (Lasmidjah Hardi, 1985: 121). Selain memberikan pakaian seadanya, Fujinkaijuga merawat dan mengusahakan pengobatan romusha yang sakit sampai sembuh. 


\section{Reaksi Kaum Wanita Terhadap Jepang}

Kehadiran Jepang dengan segala kebijakan-kebijakannya dirasakan adanya perubahan yang keras yang diterapkan oleh pemerintahan Jepang terhadap bangsa Indonesia. Kaum wanita Indonesia telah menolak keras untuk terhadap ajakan-ajakan Jepang untuk bekerjasama. Hal ini disampaikan oleh Ny. Suyatin Kartowiyono ketika terjadi pertemuan antara Shimitzu dalam suatu pertemuan mengajak kepada seluruh kaum wanita Indonesia untuk membentuk suatu perkumpulan wanita yang dinamakan Fujinkai (Perkumpulan Wanita).

Berdirinya Fujinkai mendapatkan pertentangan dari aktifis wanita Indonesia. Dan dengan adanya Fujinkai, maka Aisyiyah sebagai organisasi wanita yang telah mengakar, oleh pamerintahan Jepang dilarang melakukan gerakan sosial, yang berwenang hanyalah Fujinkai. Sejalan dengan ketentuan tersebut, maka pemeliharaan anak yatim perempuan oleh Aisyiyah terpaksa diserahkan kepada Muhammadiyah. Tetapi dalam pelaksanaannya Ny. Badillah Zuber beserta anggota-anggota Aisyiyah lainnya secara diam-diam terus melakukan kegiatannya. Mereka terus aktif mengumpulkan infak dan sedekah berupa uang atau beras dan juga mengumpulkan pakaian-pakaian bekas dari dermawan yang kemudian diberikan kepada fakir miskin.
Salah satu kegiatan yang paling menonjol ialah perayaan Nujulul Quran. Perayaan ini prakarsa guru-guru SMA Yogyakarya yang diketuai oleh $\mathrm{Ny}$. Badilah. Selain perayaan Nujulul Quran ada juga perayaan lain yang selalu dilakukan yaitu diantaraya adalah perayaan Hari Kartini sebagai penghormatan atas jasa-jasanya. Sehubungan dengan larangan yang di instruksikan pemerintahan Jepang, maka untuk memperoleh izin, Ny. Arini Suwandi beserta lima orang anggotanya menghadap pembesar Jepang yang berkedudukan di GedungAgung Yogyakarta. Dengan mengajukan berbagai alasan yang meyakinkan, pada akhirnya penguasa Jepang memberikan izin dengan beberapa syarat:

a. Tidak boleh melagukan Indonesia Raya;

b. Tidak boleh mengibarkan bendera Merah Putih;

c. Peserta didik boleh lebih dari 500 orang;

d. Waktu pelaksanaan tidak boleh lewat dari pukul 22.00

e. Untuk keamanan diadakan penjagaan oleh tentara Jepang.

(Lasmidjah Hardi, 1985: 3).

Perayaan diselenggarakan di

Gedung $\mathrm{CHTH}$ atau gedung KONI Yogyakarta. Acara berlangsung dengan tertib dan teratur. Kemudian Ny, Arini ditunjuk sebagai pimpinan Fujinkai, meskipun awalnya dia menolak, tetapi pada akhirnya bersedia juga. Dengan kehadiran Jepang di Indonesia sudah sangat menyusahkan rakyat. Kebutuhan 
sandang dan pagan semakin sukar didapat. Perintah Jepang telah menentukan jatah beras hanya 180 gram bagi setiap penduduk, padahal memperolehnya sangat sukar. (Soebagiyo IN, 1982: 58).

Bagi kaum wanita yang telah terjun dalam gerakan politik, kehadiran Jepang tidaklah berbeda dengan penjajahan Belanda, karena itu mereka tidak percaya dengan propaganda dan janj-janji Jepang. Terdapat aktivis SI perempuan di Surabaya yaitu Ny. Siti Larang Sosrokardono. Dalam menyalurkan gagasannya yang vital, Ny. Siti menyarankan supaya para pemuda masuk PETA agar para pemuda Indonesia mendapat keterampilan dan keahlian yang professional dalam bidang kemiliteranya. Dengan demikian, apabila negara merdeka, negara sudah mempunyai tentara yang tangguh. (Lasmidjah Hardi, 1984:23).

Ditengah perjalanan perjuangannya Ny. Siti Larang dijebloskan kedalam penjara. Selama dipenjara dia diperlakukan sangat tidak manusiawi. Dia disiksa dengan sangat kejam. Ada juga Trimurti yang merupakan pengasuh surat kabar Sinar Baru. Berbagai cara telah dilakukan kaum wanita untuk menentang Jepang. Ada beberap reaksi yang dilakukan oleh kaum wanita untuk menentang Jepang diantaranya yang dilakukanoleh Ny. Sri Suryan Abednegao, Ny. Mantria Hotasoit, Ny. Johana
Masdani, Ny. Syamsidar Murdiono. Beberapa reaksi nyata yang mereka lakukan diantaranya mereka tidak mau belajar bahasa Jepang, tidak menghormati orang-orang Jepang, tidak mau menghormat pada bendera Jepang dan lain-lain.

\section{Peranan Wanita Pada Masa Awal Kemerdekaan}

Dalam proses menuju proklamasi kemerdekaan kaum wanita telah memberikan tenaga dan fikiran secara maksimal seperti yang telah diperankan oleh Ny. Fatmawati Sukarno, Ny. Maria Ulfah Santosa, Ny. Suwarni Pringgodigdo, Ny. Artinah Syamsudin dan lain-lain. Mareka adalah kaum wanita yang mewakili wanita-wanita Indonesia yang ikut berjuang mengatasi kesulitan bangsa dan banyak hal yang mereka lakukan diantaranya dalam kesehatan, keterampilan, pendidikan, keperluan logistik dan lain sebagainya.

Dengan membubarkan Fujinkai, kaum wanita kemudian membentuk barisan-barisan untuk mendukung perjuangan dalam mempertahankan kemerdekaan. Pengalaman-pengalaman selama bergabung dengan Fujinkai dimanfaatkan untuk kepentingan perjuangan. Akan tetapi karena keadaan geografis Indonesia yang terdiri atas pulau-pulau menyulitkan penyebaran berita yang perlu disampaikan dalam waktu singkat. 
Organisasi-organisasi wanita di setiap daerah dibentuk, diantaranya di Jawa Tengah, Jawa Barat, Sumatra, Medan dan di daerah yang lainnya.

Sehubungan dengan itu kaum wanita Jawa Barat yang aktif mengikuti perkembangan Jakarta, dengan segera membentuk wadah perjuangan yang bergerak dalam kepalang-merahan, dapur umum, dan kegiatan lainnya. Dalam hal ini yang menghimpun tenaga wanita adalah Inspektorat Wanita di Garut, Budilstri di Bandung ataupun kaum wanita aktif dalam kelaskaran-kelaskaran bersama kaum pria (Lasmidjah Hardi, 1984:55).

Dalam rangka menyambut kemerdekaan, kaum wanita di wilayah Indonesia bagian barat, kaum khususnya kaum wanita di Sumatra Utara sampai ke Selatan bangkit bersama kaum pria secara bersamaan. Aktifitas kaum wanita bukan saja mempersiapkan diri di garis belakang seperti dapur umum, tetapi juga telah terpanggil untuk menghimpun dana perjuangan berupa barang perhiasan seperti yang dilakukan wanita Aceh. Di bawah pimpinan permaisuri Sultan Siak, telah dilakukan pengumpulan barang perhiasan untuk keperluan badan-badan perjuangan.

Untuk memperkuat barisan, maka tokoh-tokoh wanita dari Aceh, Sumatrea Timur, dan Tapanuli yang ketika itu tergabung dalam wilayah Sumatra Utara membentuk barisan Srikandi. Barisan ini dipersiapkan dengan keterampilan militer, dapur umum, dan keterampilan operator radio. Tokoh-tokoh wanita di wilayah Sumatra Utara di antaranya adalah Teungku Haji Ainal Mardhiah, Rohana Hasyim, Tjut Mariam, Tjut Mirsan dari Aceh. Sedangkan dari Sumatra Timur diantaranya adalah Ny. Mirsan dari Aceh, Ny. Ahmad Taher dari Sumatra Utara serta Ny. FL. Tobing dari Tapanuli. Tokohtok wanita ini telah berjuang dalam mempertahankan kemerdekaan secara maksimal (Manus, 1985: 43).

Kaum wanita di Sulawesi Selatan juga turut aktif bersama para pemudanya untuk berjuang menyambut kemerdekaan. Tokoh-tokoh wanita daerah ini tampil dengan mendirikan organisasi kewanitaan ataupun kelaskaran, seperti Siti Mulyati Hasyim dengan pasukan wanitanya, Ruaidah dengan Divisi Melati yang tergabung dalam melaksanakan kelaskaran Kris muda Mandar, ibu Depo Bang Samandar yang telah menantang Belanda sejak tahun 1906, Syarifah Ragwan mengikat kerjasama dengan semua pejuang, dan Ny. H.Umi Hani A. Salam yang aktif dalam dua kelaskaran yaitu duduk sebagai anggota Majelis Kewanitaan, Sekretaris Persatuan Wanita Majene (PWM), sebagai pimpinan dan anggota Laskar Wanita Melati dalam Kris Muda (NurlianaNana, 1986 84-92).

Demikianlah peran serta kaum wanita dalam menyambut dan 
mempertahankan kemerdekaan di seluruh pelosok tanah air. Kaum wanita telah menyumbangkan tenaga dan pikiran secara maksimal yang disalurkannya melalui organisasikewanitaan dan bahkan dalam kelaskaran-kelaskaran atau Barisan Srikandi baik di garis belakang maupun di garis depan.

\section{PENUTUP}

\section{Simpulan}

Sejak awal kaum wanita Indonesia sudah aktif berperan dalam perjuangan bangsa. Dapat dilihat dari keaktifan mereka pada organisasi bentukan pemerintahan Jepang maupun non pemerintahan. Untuk menampung semua kegiatan wanita, Jepang mendirikan Fujinkai baik di tingkat pusat maupun daerah. Istri-istri pamong praja diharuskan menjadi anggota Fujinkai. Adapun tugasnya adalah membantu garis depan dengan memperkuat garis belakang. Hal ini dijalankan dengan latihan kepalangmerahan, penggunaan senjata, penyelenggaraan dapur umum, mengerjakan keperluan serdadu, memperluas tanaman bahan makanan, meningkatkan populasi ternak dan menggalakkan penanaman kapas.

\section{DAFTAR PUSTAKA}

Cokrowinoto, (1988). Analisa Situasi Wanita Indonesia. Jakarta. Kantor Mentri Negara UPW.

Hadriana Marhaeni Munthe, (2003). Perkembangan Situs dan Peranan
Wanita Indonesia. Medan. Universitas Sumatra Utara.

LasmidjahHardi, (1984). Kumpulan Pengalaman dan Pemikiran. Jakarta. Sinar Harapan.

Manus, MPB (1985). Peranan Wanita Indonesia Di Masa Perang Kemerdekaan (1945-1950). Jakarta. Depdikbud

Maria Ulfah Subadio dkk, (1983). Peranan dan Kedudukan Wanita Indonesia. Yogyakarta. Gadjah Mada University Press.

Nurliana Nana, (1986). Peranan Wanita Indonesia Di Masa Kemerdekaan (1945-1950). Jakarta. Depdikbud

Mukmin Hidayat, (1980). Beberapa Aspek Perjuangan Kaum Wanita. Jakarta. Binacipta.

Panitia Kongres Wanita Indonesia, (1986). Sejarah Setengah Abad Kesatuan Pergerakan Wanita Indonesia. Jakarta. Balai Pustaka.

Ricklefs, (2011). Sejarah Indonesia Modern. Yogyakarta. UGM Press

Rochiati Wiriaatmadja, (1986). Dewi Sartika. Jakarta. Deparrtemen Pendidikan dan Kebudayaan.

Saparinah Sadili, (1988). Pengembangan Diri Wanita dalam Keluarga dan Lingkungan Sosial. Jakarta. Djambatan.

Sugiyono, (2012). Metode Penelitian Pendidikan. Bandung. Alfabeta

Suhartono, (2006). Sejarah. Jakarta. Widya Utama

Soebagiyo IN, (1982). Trimurti Wanita Pengabdi Bangsa. Jakarta. Gunung Agung 